\title{
Subcutaneous Scrotal Leiomyosarcoma -A case report
}

\author{
Nemri S.N. ${ }^{1}$, Fatima S. ${ }^{2}$, Haider N. ${ }^{3}$ \\ ${ }^{1}$ Dr. Sabah Nayef Nemri, Consultant, Department of Laboratory Medicine, Aseer Central Hospital, Abha KSA, \\ ${ }^{2}$ Dr. Sohaila Fatima, Department of Pathology, King Khalid University, Abha KSA, ${ }^{3}$ Dr. Nazima Haider Department of \\ Pathology, King Khalid University, Abha, KSA
}

Address for Correspondence: Dr. Sohaila Fatima, King Khalid University, Abha KSA, Email: sohailafatima@gmail.com

\begin{abstract}
Leiomyosarcomas are uncommon soft tissue tumors which can arise anywhere in the body. Leiomyosarcomas of the scrotum belonging to the subcutaneous superficial group are rare and do not involve the testis, epididymis or spermatic cord. Immunohistochemistry is very important to diagnose and differentiate it from other spindle shaped lesions which may arise at this site. We present a case of scrotal mass in a 87 year old male which was diagnosed as leiomyosarcomas.
\end{abstract}

Keywords: Leiomyosarcoma, Scrotum, Paratesticular

\section{Introduction}

Leiomyosarcoma (LMS) is a soft tissue tumour arising from smooth muscle cells of mesenchymal origin. It is usually seen in extremities, large vessels, retroperitoneum, superficial or deep soft tissues, rarely in bone, breast, colon, epididymis, mediastinum [1]. We report a case of LMS scrotum which was paratesticular in location a very rare site for this malignant tumor in an old male. It also highlights the importance of immunohistochemistry in differentiating it from other lesions.

\section{Case Report}

An 87 year old male was admitted with a right scrotal mass of 5 months duration. He had no significant past medical history. On physical examination there was a 6 X5 cm right scrotal mass which appeared separate from testis. The X-ray chest and whole body CT scan was normal.

Tumour markers including lactate dehydrogenase (LDH), alpha-fetoprotein (AFP) and beta-human chorionic gonadotrophin $(\beta-\mathrm{HCG})$ were within normal ranges. An ultrasonography showed a solid mass in scrotal subcutaneous tissue with cystic areas not communicating with testis.

The patient underwent resection of mass. On gross examination it was firm grey white homogenous tumor $6 \times 5 \times 2.5 \mathrm{~cm}$ with focal tiny cystic areas with skin attached. The pathologic examination revealed infiltrative hypercellular spindle cell proliferation in subcutaneous tissue (Figure 1) arranged in alternating fascicles (Figure 2A) and focal sheets of epithelioid cells with slit like and cystic spaces (Figure 2B), prominent vascular pattern (Figure 2C).

Tumor cells showed nuclear atypia and mitotic activity 13/10 HPF with background of chronic inflammatory infiltrate of lymphocytes and plasma cells (Figure 2D).

Immunostaining was positive for smooth muscle actin (SMA), CD34, calponin, S100, focally positive (Figure 3) and negative for pancytokeratin, desmin, MyoD1,CD117. It was diagnosed as high grade sarcoma favouring LMS.

Manuscript received: $26^{\text {th }}$ April 2017

Reviewed: $5^{\text {th }}$ May 2017

Author Corrected: $15^{\text {th }}$ May 2017

Accepted for Publication: $24^{\text {th }}$ May 2017 


\section{Case Report}

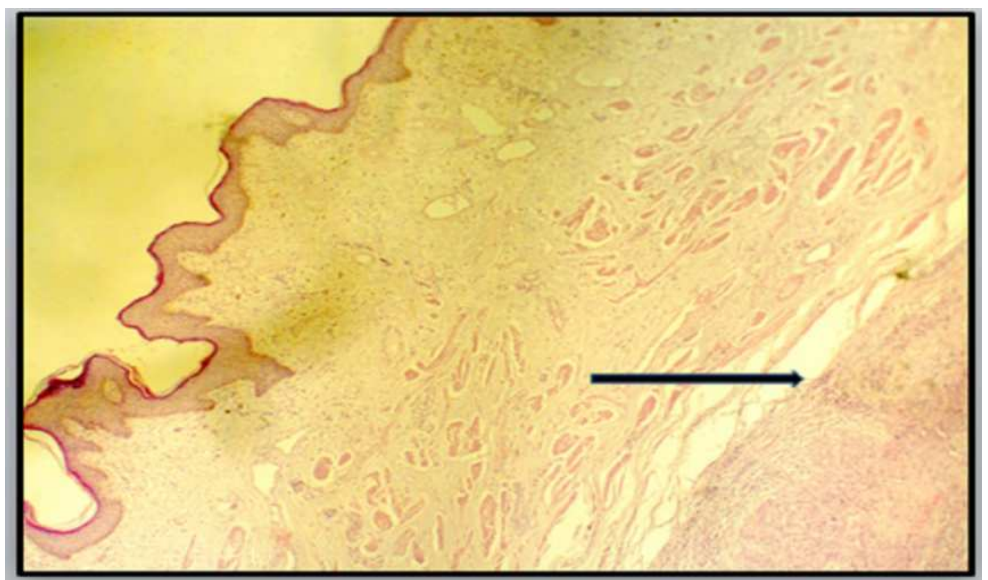

Figure-1: Section showing scrotal epidermis, dermis and tumor arising in subcutaneous tissue (Hematoxylin- eosin X 5)

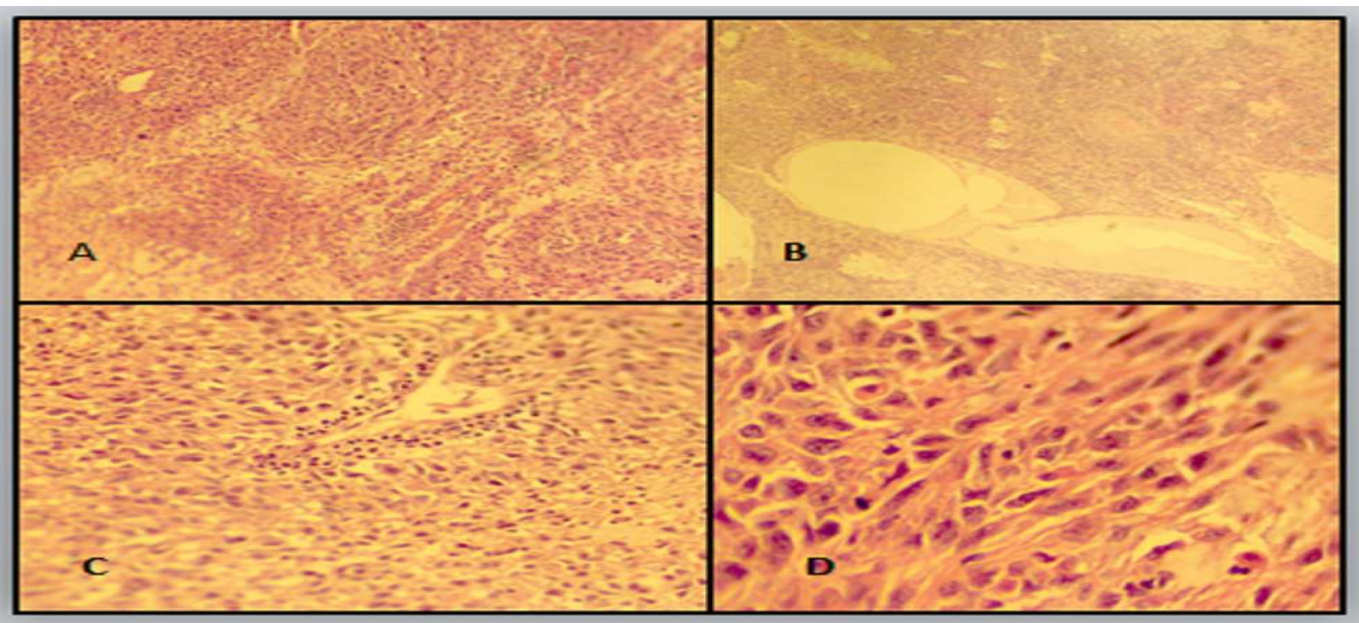

Figure-2: Sections through the tumour A: Showing atypical spindle cells arranged in fascicles (HE X 10) B: Showing cystic areas (HE X 10) C:Tumor cells arranged around vessels (HE X 20) D: showing atypical spindle cells, nuclear pleomorphism and several mitoses. ( HE X 40)

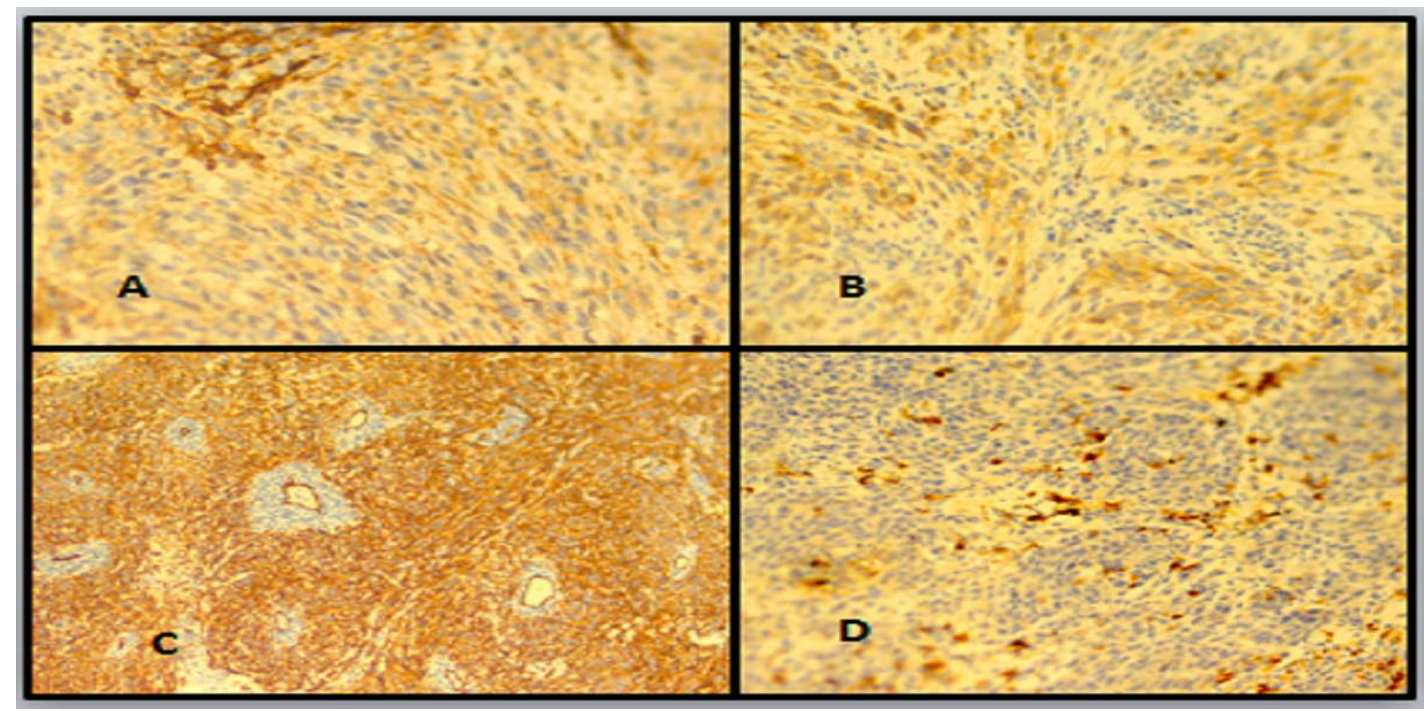

Figure-3: Immunohistochemical study by A- Smooth muscle actin B- Calponin C- CD34 D-S100 showing positivity in malignant cells (X20). 


\section{Discussion}

The malignant sarcomatous tumors in scrotum are rhabdomyosarcoma, leiomyosarcoma, liposarcoma, fibrosarcoma, malignant fibrous histiocytoma, desmoplastic round cell tumor. LMS are malignant softtissue tumours, arising from the undifferentiated smooth muscle cells of the mesenchymal origin. They are relatively rare with most being located in the extremities but they can occur anywhere including the head and neck region. Many arise from the walls of arteries and veins of widely differing caliber, ranging from large ones (inferior vena cava, saphenous vein, femoral vein, pulmonary artery, femoral artery, and aorta, in that order of frequency) to venules and arterioles [1].

LMS of the scrotum have been classified into the paratesticular and the intratesticular. Intratesticular LMS is believed to arise from the smooth muscle elements of the testicular parenchyma such as the blood vessels or the contractile cells of the seminiferous tubules. Paratesticular LMS originates from testicular tunica (48\%), spermatic cord (48\%), epididymis (2\%) and dartos muscle as well as subcutaneous tissue of the scrotum (2\%) [2].

Primary LMS of paratesticular region is seen rarely. In a series of 1583 adult soft tissue sarcomas, 14 patients $(0.8 \%)$ had paratesticular sarcoma, 4 patients $(0.25 \%)$ were paratesticular leiomyosarcomas, 5 rhabdomyosarcomas, 3 liposarcomas, 1 malignant fibrous histiocytoma, 1 undifferentiated sarcoma [3]. They belong to the group of skin or subcutaneous superficial LMS. Incidence of superficial LMS has varied from 2.3 to $5.3 \%$ of malignant soft tissue tumors and from 4.0 to $6.5 \%$ of soft tissue sarcomas [4]. They are usually seen in sixth and seventh decade presenting as a discrete, slow growing painless mass separate from the testis [5]. Frequent loss of 10q in LMS from a number of anatomical sites including the uterus suggests a common pathogenetic mechanism. In a study of extrauterine LMS, the most frequent loss was detected in 10q (20 of 29 tumors), with a minimal common overlapping region corresponding to $10 \mathrm{q} 11$ q24.44. Loss of heterozygosity did not appear to be a strong prognostic factor [6]. A high-resolution genomewide array comparative genomic hybridization analysis indicated that low- and high-grade LMS and osteosarcoma share 12 genes located in the $17 \mathrm{p}$ amplicon [7].
Ultrasound of the scrotum usually shows a wellcircumscribed, hypoechoic mass lesion with or without calcification. CT scans of the abdomen and chest are required to rule out metastasis. .Microscopically tumor cells have elongated, blunt-ended nuclei and acidophilic fibrillary cytoplasm with perinuclear cytoplasmic vacuoles. The pattern of growth is predominantly fascicular, with the tumor bundles intersecting each other at wide angles. Merging of tumor cells with blood vessel walls is an important diagnostic clue. In some cases the vascular pattern is particularly prominent, resulting in a hemangiopericytoma-like appearance.

High mitotic activity (>10/10 HPF); overly large size, necrosis or hemorrhage even with low mitotic count favour its diagnosis. Prognosis in LMS correlates primarily with tumor size and depth [1]. Subcutaneous LMS display a pattern of circumscription, and are formed of narrow, poorly defined irregular aggregates of myomatus spindle cells intertwining or growing haphazardly. The tumors often include a vascular pattern with channels ranging from capillary dimension to larger lumens as is seen in our case [4].

Spindle cell lesions most often considered in the differential diagnosis include dermatofibrosarcoma protuberans, nodular fasciitis, fibrosarcoma, malignant schwannoma, fibroma or dermatofibroma, neurofibroma, rhabdomyosarcoma, atypical fibroxanthoma, malignant fibroxanthoma, and synovial sarcoma. On immuno-histochemical staining, expression of SMA, muscle specific actin and desmin is observed in most LMS, while expression of CD34, myogenin, Ki-67, S-100 protein and cytokeratin has also been reported in some cases [8].

Etiology of LMS remains unclear, some authors have suggested local irradiation during childhood as a potential cause [9]. The most common means of spread is lymphatic, followed by hematogenous, and by local extension. The route of lymphatic dissemination may involve the external iliac, hypogastric, common iliac, and para-aortic nodes.

The lung is the primary site of blood-borne metastases. Local spread to the scrotum, inguinal canal or pelvis along the pathway of the vas deferens is possible [10]. In a study where subcutaneous LMS were treated by local excision recurrence was seen in $50 \%$ tumors [3]. 


\section{Case Report}

However there is a general consensus that all scrotal sarcomas in adults should be managed with complete urgical resection with safe margin. However, An oncologically accepted safe margin of $>10 \mathrm{~mm}$, which gives a $84 \%$ local recurrence free interval at 5-years for soft tissue sarcomas has been reported by McKee et al [11].

\section{Conclusion}

In conclusion paratesticular LMS arising from subcutaneous tissue are rare and immunohistochemistry is required for making a diagnosis and differentiating it from other spindle shaped lesions.

Funding: Nil, Conflict of interest: None initiated, Permission from IRB: Yes

\section{References}

1. Rosai J, Ackerman L: Surgical Pathology, ed 10. New York, Mosby, 2011.

2. Batra A, Marwah N, Marwah S, Gupta S, Sen R. Subcutaneous leiomyosarcoma of scrotum presenting as an exophytic mass: An unusual presentation .Ind Derm Jour online 2015; 6(3):193-5. doi: 10.4103/2229-5178. 156394

3. Russo P. Urologic sarcoma in adults. Memorial Sloan-Kettering Cancer Center experience based on a prospective database between 1982 and 1989. Urol Clin North Am. 1991 Aug;18(3):581-8.

4. Fields JP, Helwig EB. Leiomyosarcoma of the skin and subcutaneous tissue. Cancer. 1981 Jan 1;47(1): 156-69.
5. Fisher C, Goldblum JR, Epstein JI, Montgomery E. Leiomyosarcoma of paratesticular region. A clinicopathologic study. Am J Surg Pathol. 2001;25: 1143-9.

6. El-Rifai W, Sarlomo-Rikala M, Knuutila S, Miettinen M. DNA copy number changes in development and progression in leiomyosarcomas of soft tissues. Am J Pathol. 1998 Sep;153(3):985-90.

7. Marcelo L. Larramendya , Sippy Kaura, Catarina Svarvarc , Tom Bo“hlinga , Sakari Knuutilaa, Gene copy number profiling of soft-tissue leiomyosarcomas by array-comparative genomic hybridization . Cancer Genetics and Cytogenetics 2006; 94-101. doi:10.1016/j. cancergencyto.2006.01.008.

8. Hashimoto H, Daimaru Y, Tsuneyoshi M, Enjoji M. Leiomyosarcoma of the external soft tissues: a clinicopathologic, immunohistochemical, and electron microscopic study. Cancer.1986;57:2077-88.

9. Dalton DP, Rushovich AM, Victor TA, Larson R. Leiomyosarcoma of the scrotum in a man who had received scrotal irradiation as a child. J Urol. 1988; 139:136-8.

10. Dangle P, Basavaraj DR, Bhattarai S, Paul AB, Biyani CS. Leiomyosarcoma of the spermatic cord: case report and literature review. Can Urol Assoc J. 2007; $1: 55-8$

11. McKee MD, Liu Dong Feng, Brooks J, et al. The prognostic significance of margin width for extremity and trunk. J Surg Oncol . 2004;85:68 e 76.

\section{How to cite this article?}

Nemri S.N, Fatima S, Haider N. Subcutaneous Scrotal Leiomyosarcoma- A case report. Trop J Path Micro 2017;3(2):132-135.doi: 10.17511/jopm.2017.i2.10. 